\title{
A combined crystallographic and theoretical study of weak intermolecular interactions in crystalline squaric acid esters and amides
}

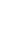

(1)

5

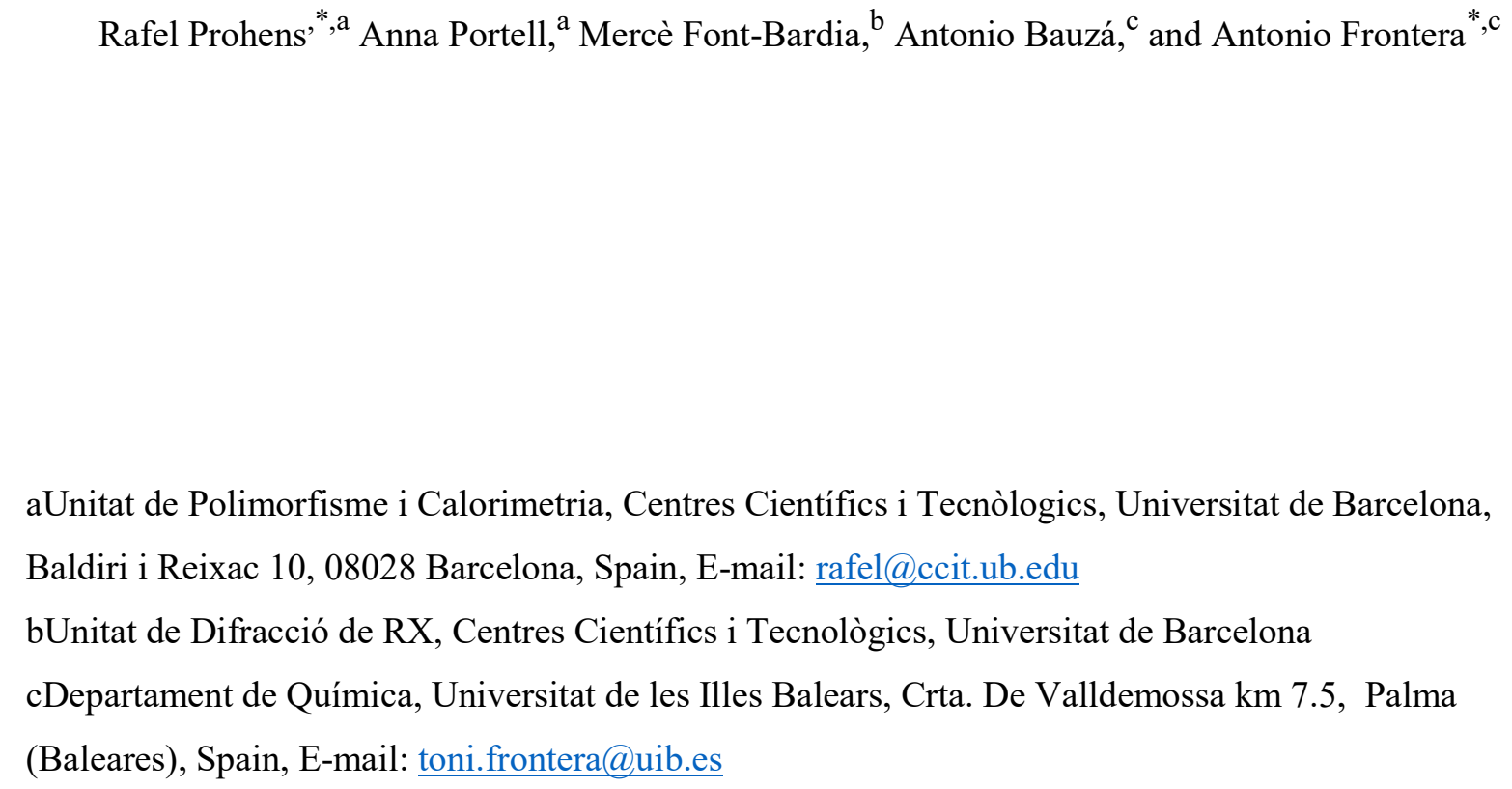




\section{ABSTRACT:}

29

30 We report the synthesis and X-ray solid state structures of five squaric acid derivatives, i.e. a

31 zwitterionic compound namely 3-Hydroxy-4-(2-pyridin-2-yl-ethylamino)-cyclobut-3-ene-1,2-dione (1);

32 a squaramide monoester, 3-Ethoxy-4-(2- pyridin-2-yl-ethylamino)-cyclobut-3-ene-1,2-dione (2); two

33 differently solvated (EtOH and DMSO/water) disquaramides 3,4-bis((4-

34 hydroxyphenethyl)amino)cyclobut-3-ene-1,2-dione (3 and 4, respectively); and a mixed hydrogen

35 squarate and disquarate 2-(2-Amino-ethyl)-pyridinium salt (5). All compounds form interesting

36 supramolecular assemblies in the solid state that have been analyzed using high level DFT calculations

37 and the Bader's theory of "atoms-in-molecules". An intricate combination of ion-pair and H-bonding

38 interactions along with $\pi-\pi$ stacking and anion $-\pi$ contacts of the cyclobutenedione rings are crucial for

39 the formation of the supramolecular assemblies in the solid state

40 


\section{INTRODUCTION}

43 Squaric acid (3,4-dihydroxy-cyclobut-3-en-1,2-dione) derivatives are highly functionalized four-

44 membered ring systems with a strong ability to form H-bonds both as donors and acceptors.

45 Remarkably, their enhanced ability for establishing hydrogen bonding compared to urea has been

46 rationalized taking into consideration the increase in the aromaticity of the four-membered ring upon the

47 formation of H-bonds. 1 Squaric acid amides, semiesters and esters are easy to synthesize and have

48 multiple applications in several fields such as catalysis,2 supramolecular chemistry3 and transmembrane

49 transport.4 Similarly to urea and thiourea, they are convenient supramolecular synthons for generating

50 interesting assemblies in the solid state. 5 In fact, the use of squarate and hydrogen squarate salts is

51 frequent in crystal engineering6 and organic material research.7 Moreover, they have been used by some

52 of us to analyze the electrostatic compression phenomenon8a that provides an explanation to the face-to-

53 face $\pi$-stacked assemblies observed in a series of zwitterionic squaric acid/squaramide compounds.8b

54 We have applied this phenomenon in the crystal engineering field combining the $\pi$-stacking of tertiary

$55 \mathrm{~N}$-alkylsquaramides with hydrophobic interactions to construct supramolecular assemblies resembling

56 lipid bilayers.9

57 In this manuscript, we have synthesized several squaric acid derivatives with different degree of

58 substitution (see Fig. 1a). That is, zwitterionic monosquaramide (1), squaramide monoester (2),

59 disquaramides (3 and 4) and finally a mixed hydrogen squarate and squarate salt (5) (2-(2-

60 ammonioethyl)pyridin-1-ium as counter-cation) have been Xray characterized with the additional

61 objective of extending the knowledge regarding the forces that govern their supramolecular assemblies

62 in the solid state. To achieve this goal, we combine crystal structure and computational analyses of these

63 five model compounds. In particular, we focus our attention on analysis of the charge assisted H-

64 bonding and $\pi$-stacking interactions involving the four membered ring.

65 


\section{EXPERIMENTAL AND THEORETICAL METHODS}

\subsection{Materials and measurements.}

All chemicals used were of reagent grade and used as received from Sigma-Aldrich

\subsection{Synthesis.}

Synthesis of 1-5 were carried out following reported methodology.12 Suitable crystals of 1 and 5 for SXRD analysis were obtained in water, while crystals of 2 were obtained in diethyl ether, crystals of 3 in ethanol and crystals of 4 in DMSO/water.

\subsection{X-ray crystallographic analysis.}

Single crystal X-ray diffraction intensity data of solid forms 2 and 3 were collected using a MAR345 diffractometer with an image plate detector, equipped with graphite monochromated MoK $\alpha$ radiation $(\lambda$ $=0.71073 \AA$ ), and for forms 1,4 and 5 data were collected using a D8 Venture system equipped with a multilayer monochromator and a Mo microfocus source $(\lambda=0.71073 \AA)$. Frames were integrated with the Bruker SAINT software package using a SAINT algorithm. Data were corrected for absorption effects using the multi-scan method (SADABS).13 The structure was solved and refined using the Bruker SHELXTL Software Package, a computer program for automatic solution of crystal structures, and refined by the full-matrix least-squares method with ShelXle Version 4.8.0, a Qt graphical user interface for the SHELXL computer program.14 A summary of crystal data and relevant refinement parameters is given in Table 1.

\subsection{Theoretical methods.}

The geometries of the complexes included in this study were computed at the M06-2X/def2-TZVP level of theory using the crystallographic coordinates within the TURBOMOLE program.18 This level of theory is adequate for studying noncovalent interactions dominated by dispersion effects like $\pi$-stacking. The basis set superposition error for the calculation of interaction energies has been corrected using the counterpoise method.19 The interaction energy $(\Delta \mathrm{E})$ has been computed by subtracting the energy of the monomers (isolated molecules) to the energy of the complex, $\Delta \mathrm{E}=\mathrm{EAB}-\mathrm{EA}-\mathrm{EB}$ ). The "atoms-inmolecules" (AIM)20 analysis of the electron density has been performed at the same level of theory using the AIMAll program.21 The supramolecular cluster approach is an appropriate strategy to estimate interaction energies in the solid state.22 In this approach, the supramolecular cluster of a crystal is formed by a given central molecule (M1) that is in contact with other Mn molecules and forms the first coordination sphere. In this manner, the molecular coordination number (MCN) is determined. This methodology has been successfully used to predict/rationalize crystal growth in a given compound.22 However, in this manuscript we have used a simpler approach to estimate the strength of the noncovalent interactions that play important roles in the crystal packing of compounds 1-5. That is, we 
103 have selected several dimers from the solid state crystal structures and evaluated the binding energies as 104 a difference between the energy of the supermolecule and the sum of the monomers.

105

106

107 


\section{RESULTS AND DISCUSSION}

\subsection{Description of squaric acid derivatives $1-5$.}

111 X-ray crystallographic characterization revealed that compound 1 crystallizes in the monoclinic system

112 with space group P21/c and one molecule of 1 in the asymmetric unit. This zwitterionic squaramide in 113 anti-conformation forms selfcomplementary dimers through $\mathrm{NH} \cdots \mathrm{O}$ hydrogen bonds stabilized by electrostatic pyridinium $\cdots$ carbonyl interactions in a zig-zag fashion. Interestingly, the phenomenon of the electrostatic compression observed by some of us in similar zwitterionic compounds8a is not observed in 1, squaramide and pyridinium rings are stacked instead.

117 Compound 2 crystallizes in the monoclinic system with space group P21/n and one molecule of 2 in the 118 asymmetric unit. A syn configuration of the amide moiety allows the formation of self-complementary 119 dimers through $\mathrm{NH}^{\cdots}$ Npyr hydrogen bonds between the best donor and the best acceptor. Each dimer is surrounded in the crystal by six equivalent dimers interacting via weak van der Waals interactions. Structures 3 and 4 are two different solvates of the same disquaramide compound. Solvate 3 crystallizes in the monoclinic system with space group $\mathrm{Cc}$ and one molecule of the bis-squaramide and one of ethanol in the asymmetric unit. Squaramide groups interacts with the expected head-to-tail R2 2(10) supramolecular synthon usually found in the disquaramides. Layers of hydrogen bonded squaramides form channels occupied by ethanol molecules interacting with the phenol groups. It is remarkable that all ethanol molecules interact with the phenol moiety of the same layer of squaramides forming an efficient hydrogen bond network while in the other side of the channel phenol groups are only weakly supported by aliphatic $\cdots$ phenol interactions. On the other hand, DMSO solvate 4 crystallizes in the monoclinic system with space group P21/c with five molecules of the bis-squaramide, four of dimethylsulfoxide and two of water in the asymmetric unit. An important difference with respect to the ethanol solvate is that DMSO molecules fill the same channels formed by head-to-tail hydrogen bonded disquaramides in a alternate configuration so half of the DMSO molecules interact as acceptors with one side of the channels and the other half with the other side. In addition, water molecules complete the intricate network of interactions Finally, squarate salt 5 crystallizes in the monoclinic system with space group P21/c and one molecule of 2- aminoethylpiridinium cation, one molecule of monosquarate anion, half molecule of the squarate dianion and two water molecules in the asymmetric unit. In the structure, trimers formed by two charge assisted hydrogen bonded squarate monoanions and one dianion are surrounded by aminoethyl piridinium cations.

140 The theoretical study is devoted to the analysis of the noncovalent forces that govern the crystal packing 141 in compounds 1-5. In Fig. 7a we represent a fragment of the Xray solid state structure of compound 1 142 (zwitterion) where the three different assemblies that control the crystal packing are present and we have 143 analyzed the noncovalent forces responsible to their formation. First, we have studied a charge assisted $144 \mathrm{H}$-bonded dimer that is shown in Fig. 7 b. The protonated pyridine is close $(1.79 \AA)$ to the O-atom of the 
anionic squaramate ring explaining the large interaction energy $(\Delta \mathrm{E} 1=-57.0 \mathrm{kcal} / \mathrm{mol})$. The second assembly is a $\pi$-stacking interaction between the pyridinium moiety and the four-membered squaramate ring. The interaction energy $(\Delta \mathrm{E} 2=-10.3 \mathrm{kcal} / \mathrm{mol})$ is stronger than conventional $\pi$-stacking interaction due to the fact that the rings are charged. Finally, self-assembled H-bonded dimers are also found in the $\mathrm{X}$-ray structure (see Fig. $7 \mathrm{~d})$ that are energetically very favored $(\Delta \mathrm{E} 3=-28.0 \mathrm{kcal} / \mathrm{mol})$. Disquaramides 3 and 4 only differ in the crystallization solvent molecules. Both compounds form infinite 1D supramolecular H-bonded chains typical of secondary disquaramides (see Fig. 1b). The final 3D architecture is generated by the antiparallel stacking of these polymeric chains (see Fig. 9a,b). In both compounds, the stacked chains are connected by the solvent molecules by means of H-bonding interactions with the phenolic groups. The main difference is that in compound 3 two adjacent stacked chains are disposed parallel and, conversely, in compound 4 they are perpendicularly arranged. This is likely due to the role of the solvent (EtOH in 3 and DMSO and water in 4) connecting the phenolic $\mathrm{OH}$ groups. We have computed the interaction energy of a H-bonded dimer retrieved from the infinite 1D chain of compound 3 (see Fig. 9c), which is $\Delta \mathrm{E} 6=-20.9 \mathrm{kcal} / \mathrm{mol}(\sim 10.5 \mathrm{kcal} / \mathrm{mol}$ per H-bond). Such large interaction energy is due to the increase in the aromaticity of the four membered ring upon the formation of the dimer, as previously demonstrated by some of us.1,26 We have also evaluated the antiparallel $\pi$-stacking interaction in both compounds (see models in Fig. 9d,e). The $\pi$-stacking of both four-membered rings is complemented with two Tshaped (or $\mathrm{C}-\mathrm{H} \cdots \pi$ ) aromatic interactions involving the phenolic rings in both compounds, thus explaining the large interaction energies. The $\pi$-stacked dimer is $4.2 \mathrm{kcal} / \mathrm{mol}$ less favorable in 4 than in 3 (shorter $\pi-\pi$ stacking but longer $\mathrm{C}-\mathrm{H} \cdots \pi$ interactions). Since the dimers are also connected via the $\mathrm{OH}$ groups by the solvent molecules, this difference in energy is likely compensated by the stronger ability of DMSO and water with respect to EtOH to participate in H-bonding interactions. Compound 5 is a mixed salt composed by the diprotonated 2- (2-Amino-ethyl)-pyridine salt and both hydrogen squarate and squarate as counter-ions. In Fig. 10a we have represented a fragment of the X-ray structure and it can be observed the existence of ladders of di-squarate anions surrounded by two symmetric ladders of the dication that also interact with ladders of mono-squarate anions. Since the three main compounds are charged, the main force is the electrostatic attraction between the counterions that is a priori a nondirectional interaction. However, weaker H-bonds and $\pi$-interactions are able to finely tune their final assembly in the crystal packing. We have analyzed the self-assembled fragment highlighted in Fig. 10a. It can be observed the formation of a dimer by stabilized by strong $\mathrm{N}+-\mathrm{H}^{\cdots}-\mathrm{O}-$ $\mathrm{C}$ and $\mathrm{C}-\mathrm{H} \cdots \mathrm{O}$ H-bonds (1.76 $\AA$ and $2.31 \AA$, respectively) between the protonated pyridine moiety and the squarate dianion. Remarkably, this dimeric moiety forms a parallel displaced $\pi$-stacking interaction with another dimer. A close examination of this assembly (see Fig. 10b) reveals the existence of two symmetrically related anion- $\pi$ interactions 27 between the anionic $\mathrm{O}$ atom of the squarate and the protonated pyridine ring. This anion- $\pi$ interaction is remarkably short ( $3.1 \AA$ from $O$ to the ring centroid) due to the cationic 
nature of the $\pi$-system. The binding energy of this assembly (considering the H-bonded dimers previously formed) is very large and negative $(\Delta \mathrm{E} 9=-75.5 \mathrm{kcal} / \mathrm{mol})$ due to the electrostatic (ion-pair) nature of the interaction.

185 Finally, we have used the Bader's theory of atoms in molecules20 to characterize the interactions described in Figs. 7 to 10. In Fig. 11 we represent the distribution of critical points (CPs) and bond paths for the assemblies governed by $\pi$-interactions. Those governed by H-bonding interactions are given in the ESI (see Fig. S1). The existence of a bond CP and bond path connecting two atoms is clear evidence of interaction, since it indicates that electron density is accumulated between the nuclei that are linked by the associated atomic interaction line. 28 The distribution of CPs in the $\pi$-stacking assembly of compound 1 shows the existence of four bond CPs (red spheres) and bond paths connecting three carbon atoms and the exocyclic $\mathrm{N}$ atom of the squaramate to the pyridinium ring, thus confirming the $\pi-\pi$ interaction. The distribution also shows several ring CPs (yellow spheres) and a cage CP (green sphere) that further characterize the $\pi-\pi$ interaction. In compound 2 the $\pi$-stacking interaction is characterized by a bond $\mathrm{CP}$ and bond path inter-connecting the four and six membered rings. Moreover, the $\mathrm{CH} \cdots \mathrm{N}$ interaction is also confirmed since a bond $\mathrm{CP}$ and bond path connect the $\mathrm{CH}$ bond to the nitrogen atom of pyridine. In compound 3 it is interesting to highlight both T-shape stacking interactions (or $\mathrm{CH}^{\cdots} \pi$ 198 interactions). One is characterized by a single bond $\mathrm{CP}$ and bond path connecting one aromatic $\mathrm{H}$ atom 199 of one molecule to the aromatic carbon atom of the other molecule. The other one is characterized by 200 two bond $\mathrm{CPs}$ and bond paths interconnecting two aromatic $\mathrm{H}$ atoms to two aromatic carbon atoms (see Fig. 10c). Due to the formation of a supramolecular ring, a ring critical point also appears upon complexation. Finally, in complex 5 the anion $-\pi$ interaction is characterized by the presence of a bond $\mathrm{CP}$ that connects the $\mathrm{O}$ atom of the di-squarate moiety to the pyridine ring. This $\mathrm{O}$ atom also participates in a hydrogen bonding interaction that further contributes to the formation of the assembly 


\section{CONCLUSIONS}

207

208 Five new squaric acid derivatives have been synthesized and characterized by single crystal X-ray

209 diffraction. The small ring is highly functionalized with strong H-bond donor and acceptors groups, thus

210 forming interesting assemblies in their solid state architecture. The noncovalent interactions that govern

211 the crystal packing have been analyzed by means of DFT (M06-2X) calculations and the AIM theory.

212 The $\pi$-system of the squaric acid derivatives is able to establish a series of $\pi$-interactions, including

213 stacking and anion- $\pi$ in addition to the expected H-bonding interactions. They have been evaluated

214 energetically and characterized using the distribution of critical points and bond paths. 


\section{ACKNOWLEDGEMENTS}

217

218 AB and AF thank DGICYT of Spain (projects CTQ2014-57393-C2-1-P, FEDER funds) for funding and 219 the CTI (UIB) for free allocation of computer time.

220 

2002, 8, 433-438.

(a) D. Enders, U. Kaya, P. Chauhan, D. Hack, K. Deckers, R. Puttreddy and K. Rissanen, Chem. Commun., 2016, 52, 1669-1672; (b) A. S. Kumar, T. P. Reddy, R. Madhavachary and D. B. Ramachary, Org. Biomol. Chem., 2016, 14, 5494-5499; (c) D. Zhou, Z. Huang, X. Yu, X. Y. Wang, J. Li, W. Wang and H. Xie, Org. Lett., 2015, 17, 5554-5557; (d) L. Chen, Z.-J. Wu, M.L. Zhang, D.-F. Yue, X.-M. Zhang, X.-Y. Xu and W.-C. Yuan, J. Org. Chem., 2015, 80, 1266812675; (e) B. Shan, Y. Liu, R. Shi, S. Jin, L. Li, S. Chen and Q. Shu, RSC Adv., 2015, 5, 96665-96669; (f) M.-X. Zhao, H.-K. Zhu, T.-L. Dai and M. Shi, J. Org. Chem., 2015, 80, 11330-11338; (g) J. Peng, B.-L. Zhao and D.-M. Du, Adv. Synth. Catal., 2015, 357, 36393647; (h) W. Sun, L. Hong, G. Zhu, Z. Wang, X. Wei, J. Ni and R. Wang, Org. Lett., 2014, 16, 544; (i) X.-B. Wang, T.-Z. Li, F. Sha and X.-Y. Wu, Eur. J. Org. Chem., 2014, 739; (j) V. Kumar and S. Mukherjee, Chem. Commun., 2013, 49, 11203-11205; (k) K. S. Yang, A. E. Nibbs, Y. E. Turkmen and V. H. Rawal, J. Am. Chem. Soc., 2013, 135, 16050-16053; (1) P. Kasaplar, C. Rodriguez-Escrich and M. A. Pericas, Org. Lett., 2013, 15, 3498-3501; (m) P. Kasaplar, P. Riente, C. Hartmann and M. A. Pericas, Adv. Synth. Catal., 2012, 354, 2905-2910. (a) R. B. P. Elmes, P. Turner and K. A. Jolliffe, Org. Lett., 2013, 15, 5638-5641; (b) K. Bera and I. N. N. Namboothiri, Chem. Commun., 2013, 49, 10632-10634; (c) C. Jin, M. Zhang, L. Wu, Y. Guan, Y. Pan, J. Jiang, C. Lin and L. Wang, Chem. Commun., 2013, 49, 2025-2027; (d) C. Lopez, E. Sanna, L. Carreras, M. Vega, C. Rotger and A. Costa, Chem. - Eur. J., 2013, 8, 8487; (e) B. Soberats, L. Martinez, E. Sanna, A. Sampedro, C. Rotger and A. Costa, Chem. - Eur. J., 2012, 18, 7533-7542; (f) V. Amendola, L. Fabbrizzi, L. Mosca and F.-P. Schmidtchen, Chem. - Eur. J., 2011, 17, 5972; (g) S. Tomas, R. Prohens, G. Deslongchamps, P. Ballester and A. Costa, Angew. Chem., Int. Ed., 1999, 38, 2208-2211.

N. Busschaert, I. L. Kirby, S. Young, S. J. Coles, P. N. Horton, M. E. Light and P. A. Gale, Angew. Chem., Int. Ed., 2012, 51, 4426-4430 .

(a) A. Portell and R. Prohens, Cryst. Growth Des., 2014, 14, 397-400; (b) A. Portell, X. Alcobe, L. M. Lawson Daku, R. Cerny and R. Prohens, Powder Diffr., 2013, 28, S470-S480; (c) R. Prohens, A. Portell and X. Alcobe, Cryst. Growth Des., 2012, 12, 4548-4553.

(a) T. Kolev, R. W. Seidel, H. Mayer-Figge, M. Spiteller, W. S. Sheldrick and B. B. Koleva, Spectrochim. Acta, Part A, 2009, 72, 502-509; (b) T. Kolev, H. Mayer-Figge, R. W. Seidel, W. S. Sheldrick, M. Spiteller and B. B. Koleva, J. Mol. Struct., 2009, 919, 246-254; (c) B. Ivanova and M. Spiteller, Spectrochim. Acta, Part A, 2010, 77, 849-855; (d) S. L. Georgopoulos, H. G. M. Edwards and L. F. C. De Oliveira, Spectrochim. Acta, Part A, 2013, 111, 54-61. 
(a) C. Qin, Y. Numata, S. Zhang, X. Yang, A. Islam, K. Zhang, H. Chen and L. Han, Adv. Funct. Mater., 2014, 24, 3059-3066; (b) Z. Dega-Szafran, G. Dutkiewicz and Z. Kosturkiewicz, J. Mol. Struct., 2012, 1029, 28-34; (c) P. Barczyński, Z. Dega-Szafran, A. Katrusiak and M. Szafran, J. Mol. Struct., 2012, 1018, 28-34.

(a) A. Portell, M. Font-Bardia and R. Prohens, Cryst. Growth Des., 2013, 13, 4200-4203. (b) R. Prohens, A. Portell, M. Font-Bardia, A. Bauzá and A. Frontera, Cryst. Growth Des., 2014, 14, $2578-2587$

9 R. Prohens, A. Portell, M. Font-Bardia, A. Bauzá and A. Frontera, CrystEngComm, 2016, 18,

10 F. H. Allen, C. A. Baalham, J. P. M. Lommerse and P. R. Raithby, Acta Crystallogr., Sect. B: Struct. Sci., 1998, 54, 320-329.

(a) M. Barceló-Oliver, C. Estarellas, A. Garcia-Raso, A. Terrón, A. Frontera, D. Quiñonero, E. Molins and P. M. Deyà, CrystEngComm, 2010, 12, 362-365; (b) M. Barceló-Oliver, C.

Estarellas, A. Garcia-Raso, A. Terrón, A. Frontera, D. Quiñonero, I. Mata, E. Molins and P. M. Deyà, CrystEngComm, 2010, 12, 3758-3767.

R. Prohens, S. Tomas, J. Morey, P. M. Deya, P. Ballester and A. Costa, Tetrahedron Lett., 1998, 39, 1063-1066.

SADABS Bruker AXS, Madison, Wisconsin, USA, 2004; SAINT, Software Users Guide, Version 6.0, Bruker Analytical X-ray Systems, Madison, WI, 1999; G. M. Sheldrick, SADABS v2.03: Area-Detector Absorption Correction, University of Göttingen, Germany, 1999; Saint Version 7.60A, Bruker AXS, 2008; SADABS V. 2008-1, 2008.

A. Boultif and D. Loue, J. Appl. Crystallogr., 1991, 24, 987-993.

R. Ahlrichs, M. Bär, M. Häser, H. Horn and C. Kölmel, Chem. Phys. Lett., 1989, 162, 165-169.

S. F. Boys and F. Bernardi, Mol. Phys., 1970, 19, 553-566.

R. F. W. Bader, Chem. Rev., 1991, 91, 893-928.

T. A. Keith, AIMAll (Version 13.05.06), TK Gristmill Software, Overland Park KS, USA, 2013.

(a) M. A. P. Martins, C. P. Frizzo, A. C. L. Martins, A. Z. Tier, I. M. Gindri, A. R. Meyer, H. G. Bonacorso and N. Zanatta, RSC Adv., 2014, 4, 44337-44349; (b) M. A. P. Martins, A. R. Meyer, A. Z. Tier, K. Longhi, L. C. Ducati, H. G. Bonacorso, N. Zanatta and C. P. Frizzo, CrystEngComm, 2015, 17, 7381-7391; (c) C. P. Frizzo, A. Z. Tier, I. M. Gindri, A. R. Meyer, G. Black, A. L. Belladona and M. A. P. Martins, CrystEngComm, 2015, 17, 4325-4333. 
29424 N. C. Lim, M. D. Morton, H. A. Jenkins and C. J. Bruckner, Organomet. Chem., 2003, 68, $2959233-9241$.

29625 A. Portell, X. Alcobe, M. Latevi, R. Cerny and R. Prohens, Powder Diffr., 2013, 28, S470297 S480.

29826 D. Quiñonero, A. Frontera, P. Ballester, P. M. Deyà, Tetrahedron Lett, 41, 2000, 2001-2005 29927 (a) D. Quiñonero, C. Garau, C. Rotger, A. Frontera, P., Ballester, A. Costa and P. M. Deyà, 300 Angew. Chem. Int. Ed., 2002, 41, 3389-3392; (b) A. Frontera, P. Gamez, M. Mascal, T. J. Mooibroek and J. Reedijk, Angew. Chem. Int. Ed., 2011, 50, 9564-9583; (c) C. Estarellas, A. 302 Frontera, D. Quiñonero and P. M. Deyà, Angew. Chem. Int. Ed. 2011, 50, 415-418.

30328 R. F. W. Bader, J. Phys. Chem. A, 1998, 102, 7314-7323. 


\section{Legends to figures}

307 Figure. 1 (a) Squaric acid derivatives 1 to 5 studied in this work. (b) H-bonding patterns typical for 308 squaramide monoesters and secondary disquaramides.

309

310

Figure. 2 Crystal structure of 1 showing the most relevant interactions

Figure. 3 Crystal structure of 2 showing self-complementary dimers

Figure. 4 Crystal structure of 3 showing ethanol channels

Figure 5. Crystal structure of 4 showing DMSO channels

Figure 6 Crystal structure of 5 showing charge assisted hydrogen bonds

Figure 7 a) X-ray fragment of compound 1. H-atoms omitted for clarity (b-d) Theoretical models used to evaluate the noncovalent interactions. Distances in $\AA$.

322

Figure 8 (a) X-ray fragment of compound 2. H-atoms omitted for clarity $(b, c)$ Theoretical models used to evaluate the noncovalent interactions. Distances in $\AA$.

325

326

Figure $9(a, b) X$-ray fragments of compound 3 and 4. (c-e) Theoretical models used to evaluate the noncovalent interactions. Distances in $\AA$.

Figure 10 (a) X-ray fragment of compound 5. (b,c) Theoretical models used to evaluate the noncovalent

Figure 11 Distribution of bond, ring and cage critical points (red, yellow and green spheres, respectively) and bond paths for several assemblies of compounds 1 (a), 2 (b), 3 (c) and 5 (d). 


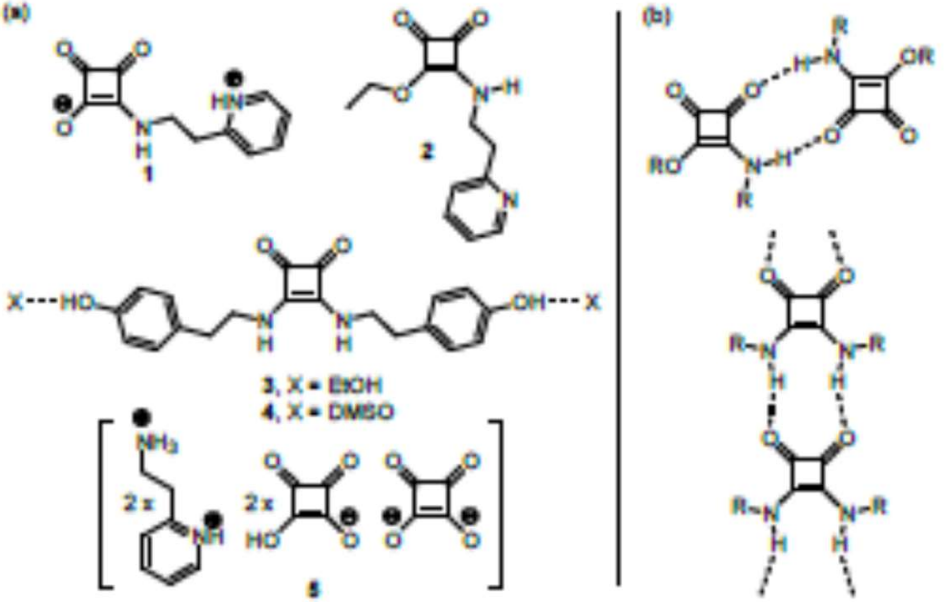




\section{FIGURE 2}

345

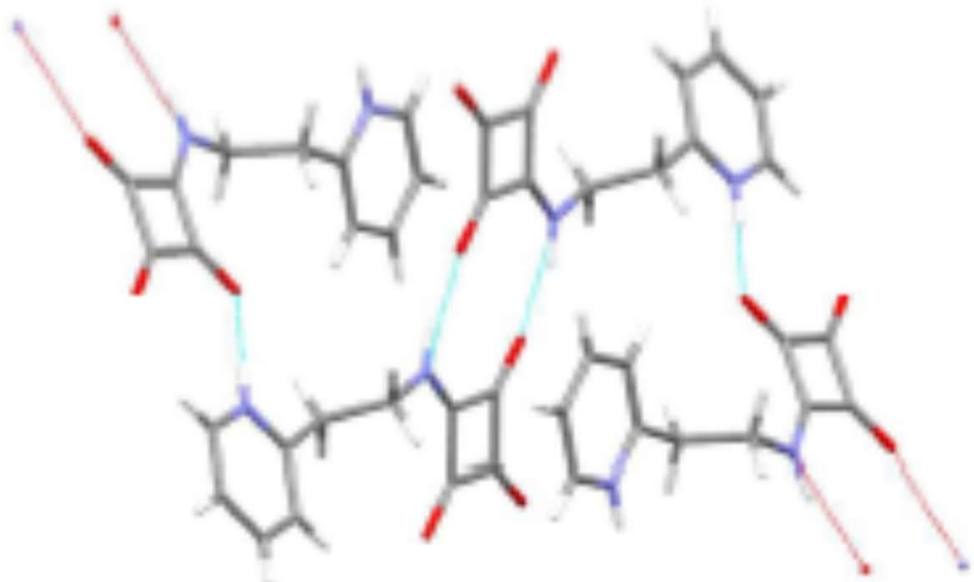


FIGURE 3

351

352

353

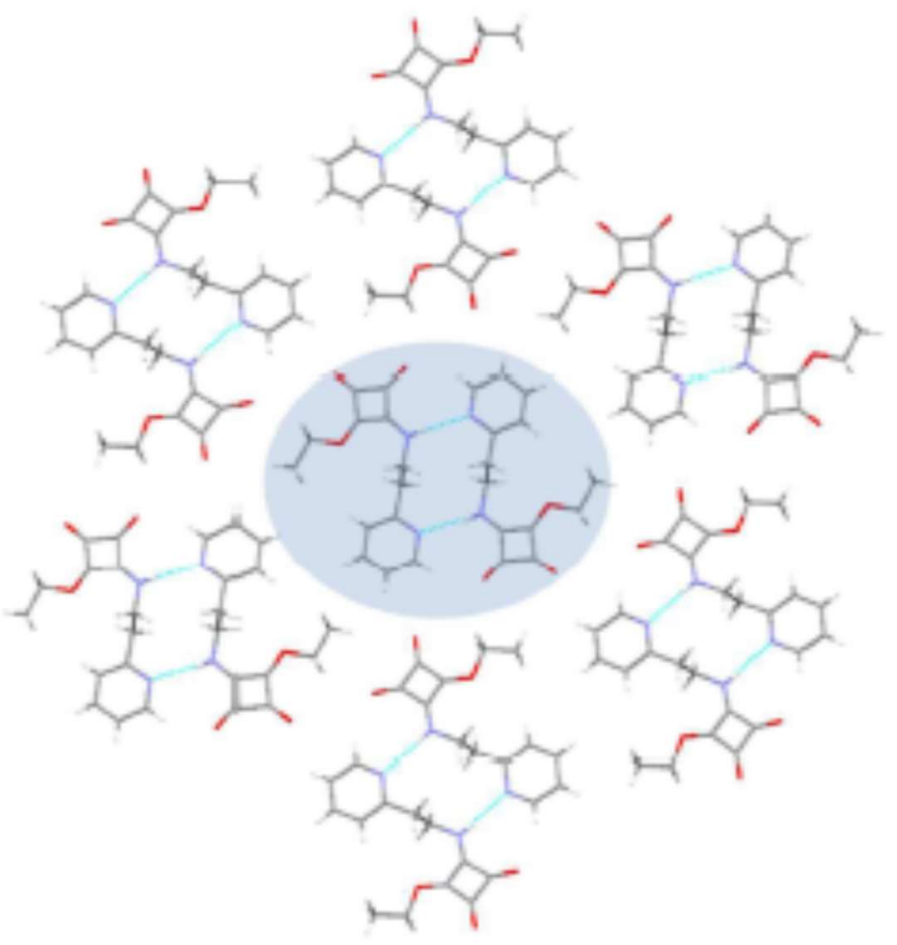

354 


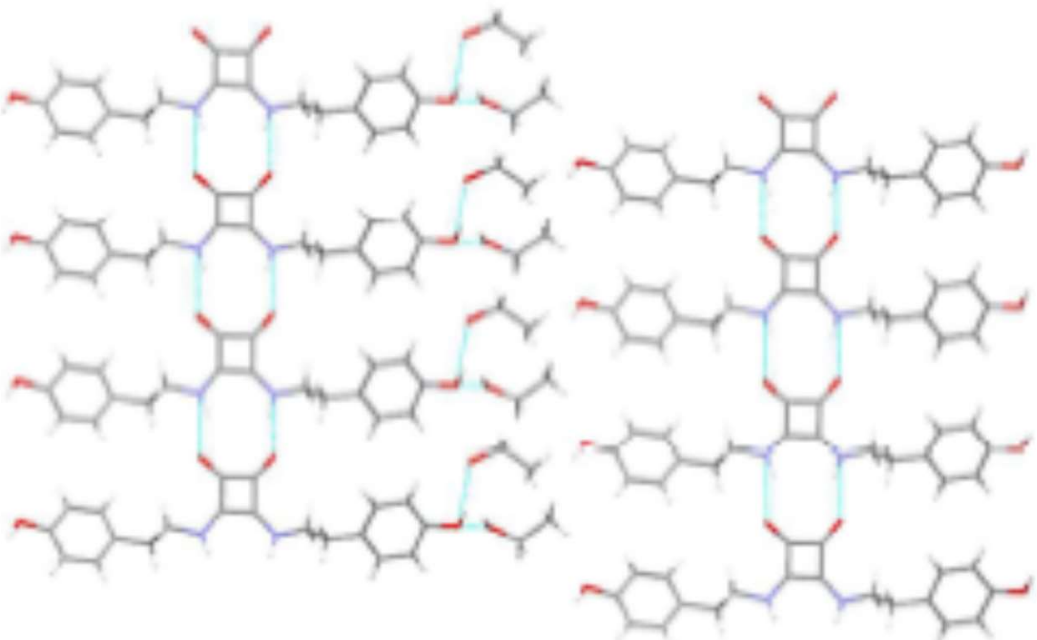

358 
361

362

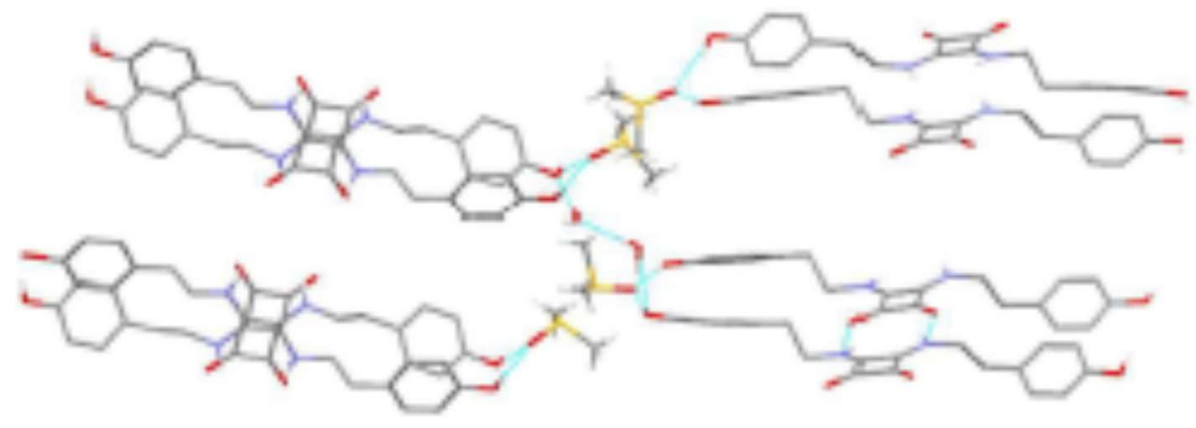

364 
366

367

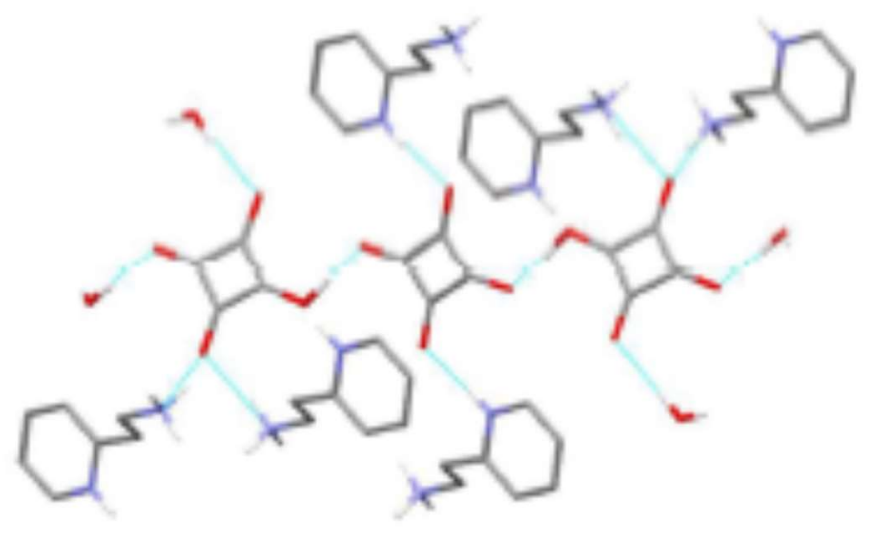

368 


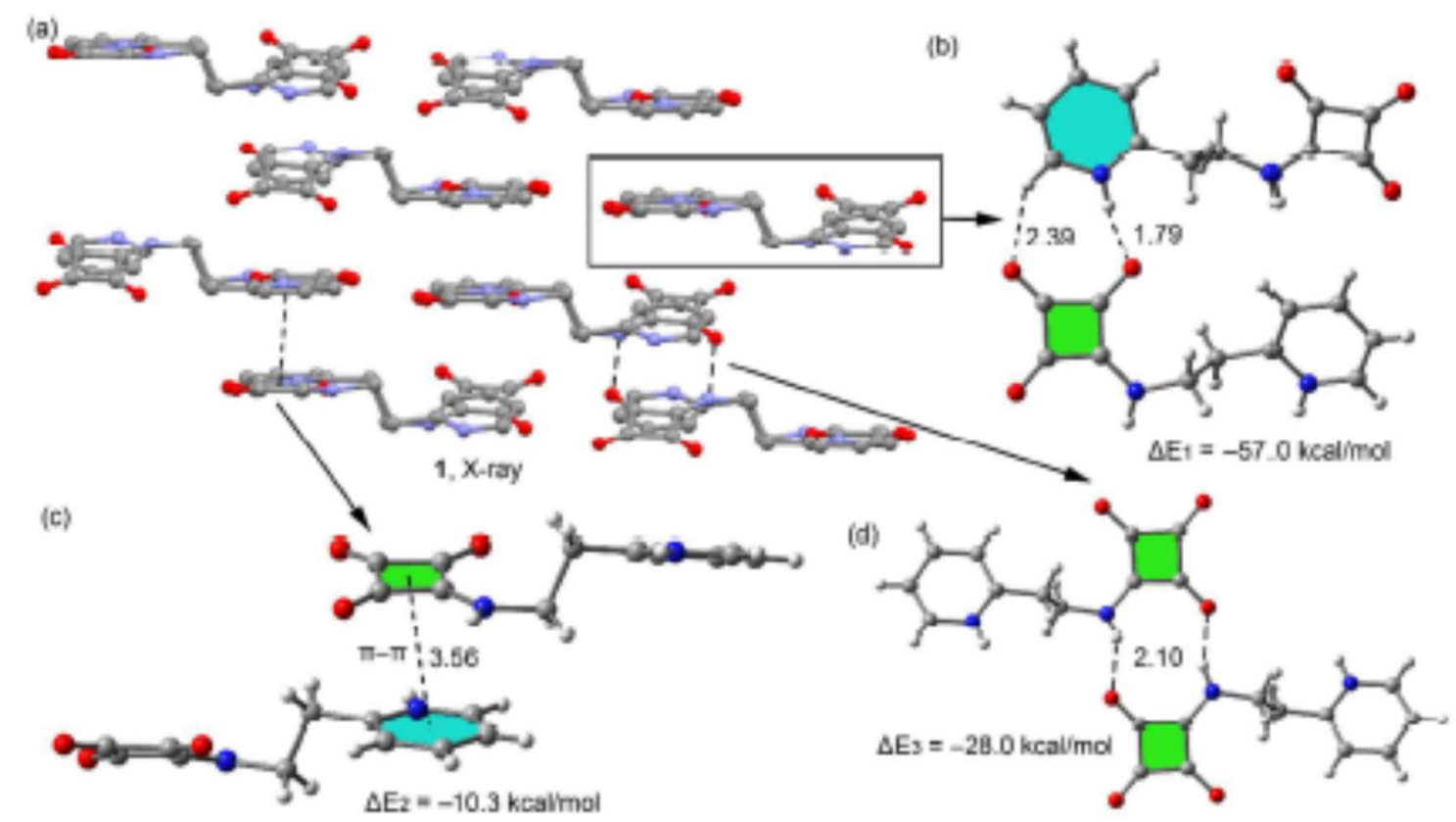


376

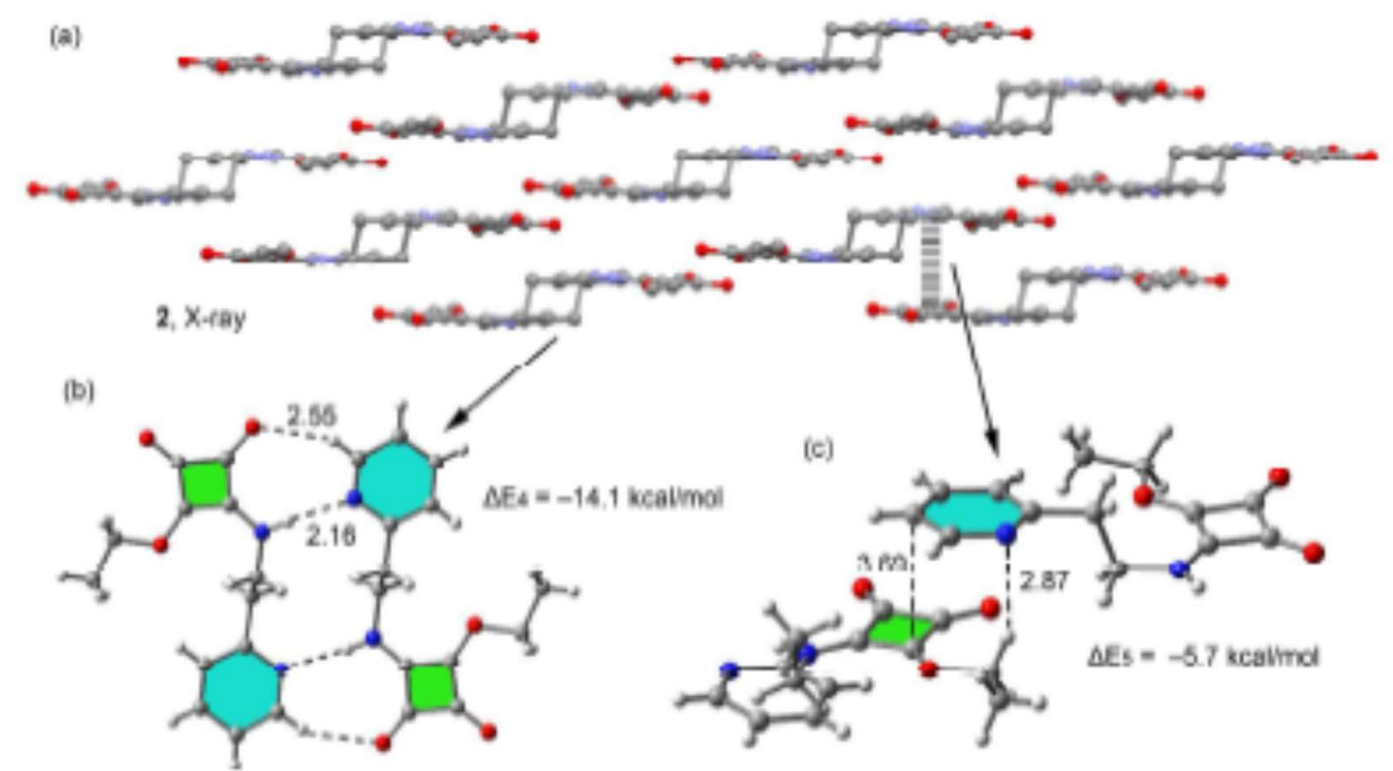


(a)

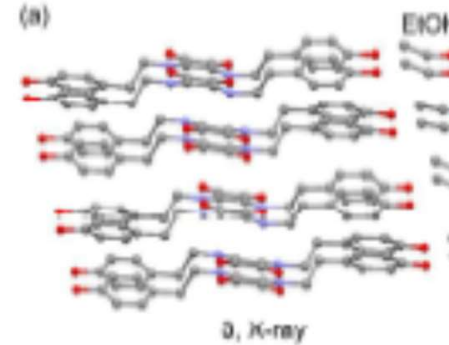

NOH

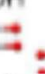
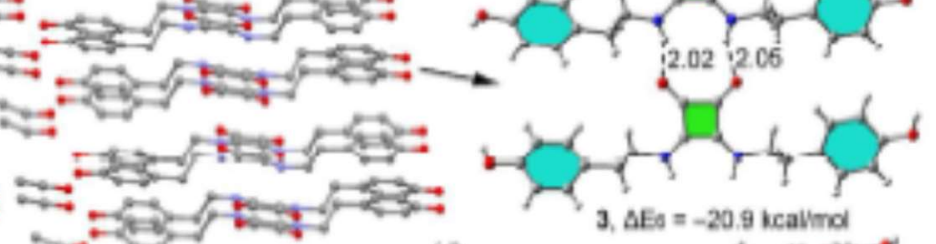

(b)

383

384 (c)

(d)

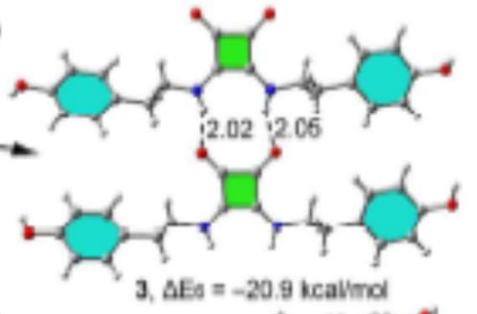

(a)

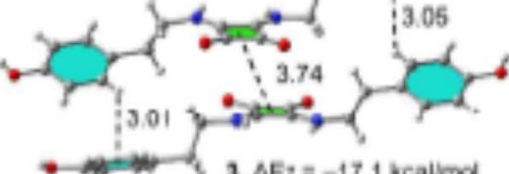

(e)

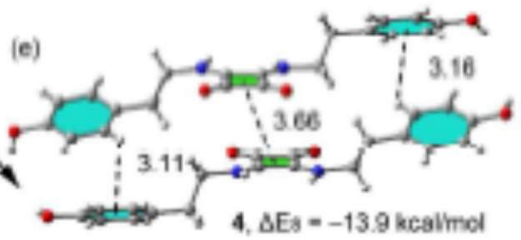

4. $\Delta E s=-13.9 \mathrm{kcalmal}$
4. $x-18 y$

I DMSO

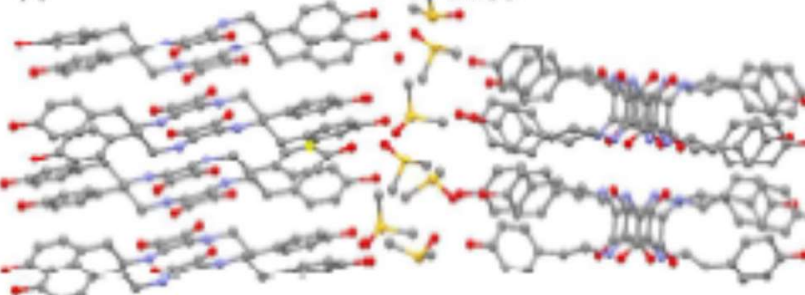


386

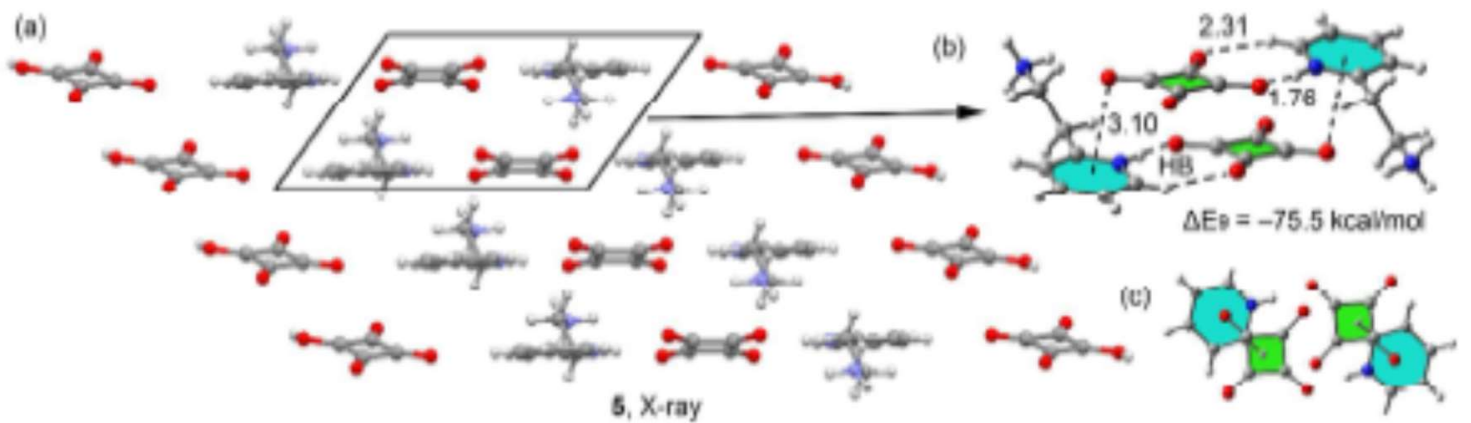


390

391
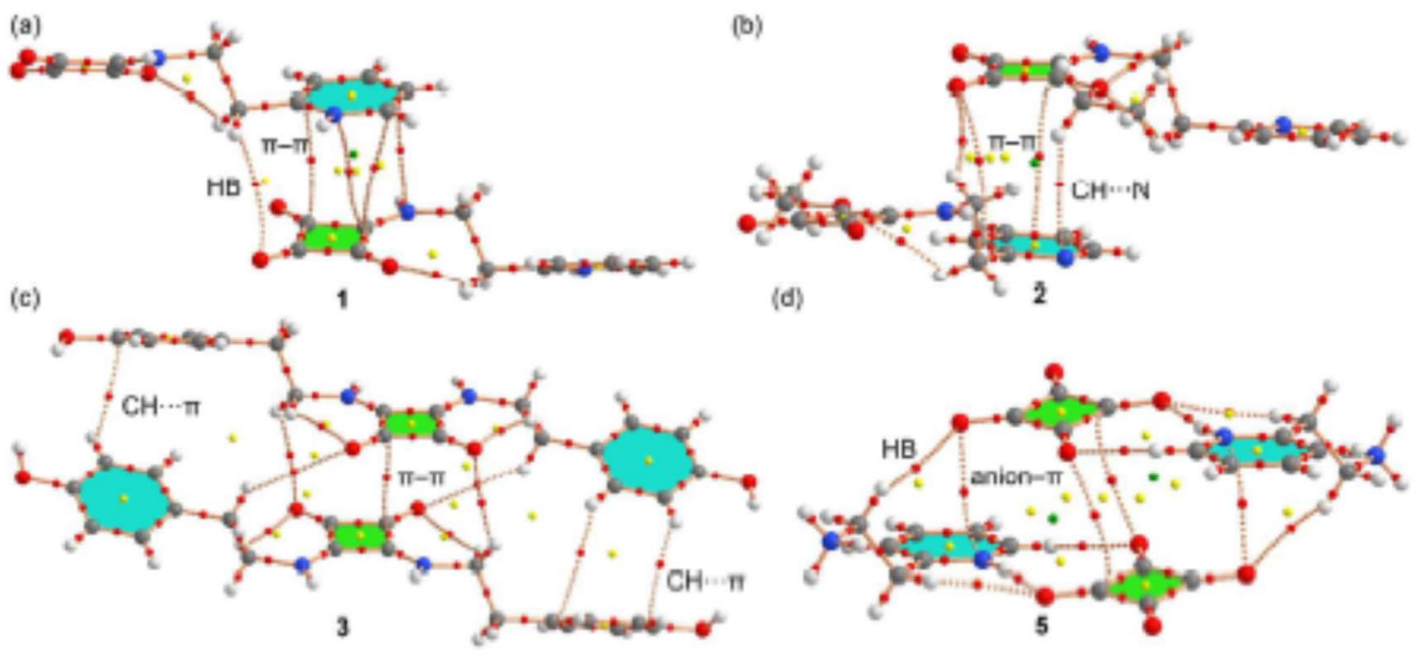

393

394 
395 Table 1 Crystallographic data and refinement details of compounds 1-5

\begin{tabular}{|c|c|c|c|c|c|}
\hline Structure & 1 & 2 & 3 & 4 & 5 \\
\hline Empirical formula & $\mathrm{C}_{2} \mathrm{H}_{20} \mathrm{~N}_{2} \mathrm{O}$ & $\mathrm{C}_{2} \mathrm{H}_{3} \mathrm{~N}_{2} \mathrm{O}_{4}$ & $\mathrm{C}_{4} \mathrm{H}_{24} \mathrm{~N}_{4} \mathrm{O}_{2}$ & $\mathrm{C}_{13} \mathrm{H}_{23} \mathrm{~N}_{22} \mathrm{O}_{3} \mathrm{~S}_{4}$ & $\mathrm{C}_{3} \mathrm{H}_{3} \mathrm{~N}_{2} \mathrm{O}_{3}$ \\
\hline Formuls Weight & 218.21 & 246.26 & 796.89 & 2110.44 & 329.28 \\
\hline Temperature $\langle K\rangle$ & $303(2)$ & $293(2)$ & $293[2]$ & $303(2)$ & $100(2]$ \\
\hline Waverength $(A)$ & 0.71073 & 0.71073 & 0.71073 & 0.71073 & 0.71073 \\
\hline Cryetal system & Monocínic & Monocínic & Monoclinic & Monoclinic & Monoclinic \\
\hline Spoce group & $P 2_{1} / c$ & $P 2_{t} / n$ & $c c$ & $P 2_{2} / c$ & $P 2 / / c$ \\
\hline \multirow[t]{3}{*}{$0,0, c(A)$} & $7.1058(13)$ & $7.435|5|$ & $46.92(5)$ & $23.485 \mid 10]$ & $4.7188(6)$ \\
\hline & $10.956(2)$ & $14.028|7|$ & $6.086[4]$ & $9.632(4)$ & $15.4660(14)$ \\
\hline & $14.797(3)$ & $12.008 / 6 \mid$ & $7.467[8]$ & $47.030[19]$ & $20.0360(18)$ \\
\hline \multirow[t]{3}{*}{$a, \beta, \gamma\left({ }^{\circ}\right)$} & 90 & 90 & 90 & 90 & 90 \\
\hline & $118.699|7|$ & $92.07(3)$ & $92.72[6]$ & $96.764[10)$ & $99.372(4)$ \\
\hline & 90 & 90 & 90 & 90 & 90 \\
\hline volume $\left(A^{\prime}\right)$ & $1010.4(3)$ & $12916(12)$ & $2130(4)$ & $10564(8)$ & $1442.7(3)$ \\
\hline$z$ & 4 & 4 & 2 & 4 & 4 \\
\hline$\delta($ calc $)\left(\mathrm{Mg} / \mathrm{m}^{\prime}\right)$ & 1.434 & 1.307 & 1.243 & 1.327 & 1.516 \\
\hline Absorption & 0.107 & 0.094 & 0.088 & 0.170 & 0.127 \\
\hline \multicolumn{6}{|l|}{ coefficient $\left(\mathrm{mm}^{-1}\right)$} \\
\hline$F(000)$ & 496 & 520 & 848 & 4472 & 692 \\
\hline $\begin{array}{l}\theta \text { range for dats } \\
\text { collection (") }\end{array}$ & 2.43 to 25.00 & 2.90 to 30.33 & 1.74 to 32.32 & 2.16 to 25 & 2.06 to 23.28 \\
\hline $\begin{array}{l}\text { Reflections } \\
\text { collected / unique }\end{array}$ & $4251 / 988$ & $11149 / 3058$ & $6362 / 3820$ & $173437 / 18613$ & $12689 / 2071$ \\
\hline $\begin{array}{c}\text { Dats/restraints/por } \\
\text { ameters }\end{array}$ & $988 / 0 / 143$ & $3098 / 3 / 164$ & $3820 / 13 / 241$ & $18613 / 13 / 1393$ & $2071 / 0 / 208$ \\
\hline $\begin{array}{c}\text { Goodness-or-fit on } \\
F_{2}\end{array}$ & 1.096 & 1160 & 0.973 & 0.630 & 1.024 \\
\hline $\begin{array}{l}\text { Fins } R \text { indices } \| 1> \\
\qquad 2 \sigma \mid \|]\end{array}$ & $R 1=0.0679, w R 2=0.1707$ & $\begin{aligned} R 1 & =0.0475, W R 2 \\
& =0.1278\end{aligned}$ & $\begin{array}{l}R 1=0.0758, \\
W R 2=0.2012\end{array}$ & $R 1=0.0364, w R 2=0.0514$ & $\begin{array}{l}R 1=0.0337, \\
W R 2=0.0840\end{array}$ \\
\hline $\mathrm{R}$ indices (all data) & $R 1=0.0729, w R 2=0.1735$ & $\begin{array}{l}R 1=0.0536 \\
W R 2=0.1312\end{array}$ & $\begin{array}{l}\mathrm{RL}=0.1222, \\
\mathrm{WR2}=0.2424\end{array}$ & $R 1=0.1991, w R 2=0.0626$ & $\begin{array}{l}R 1=0.0471 \\
W R 2=0.0916\end{array}$ \\
\hline $\begin{array}{l}\text { Largest ditr. pesik } \\
\text { and hole }\left(e . A^{\prime}\right)\end{array}$ & $0.172,-0.281$ & $0.200,-0.305$ & $0.479,-0.452$ & $0.262,-0.159$ & $0.171,-0.294$ \\
\hline $\operatorname{CCDC}$ & 1539382 & 1539383 & 1015653 & 1017985 & 1539395 \\
\hline
\end{tabular}


400 We report the synthesis and X-ray solid state structures of five squaric acid derivatives. All compounds 401 form interesting supramolecular assemblies in the solid state that have been analyzed using high level 402 DFT calculations.

403

404

405

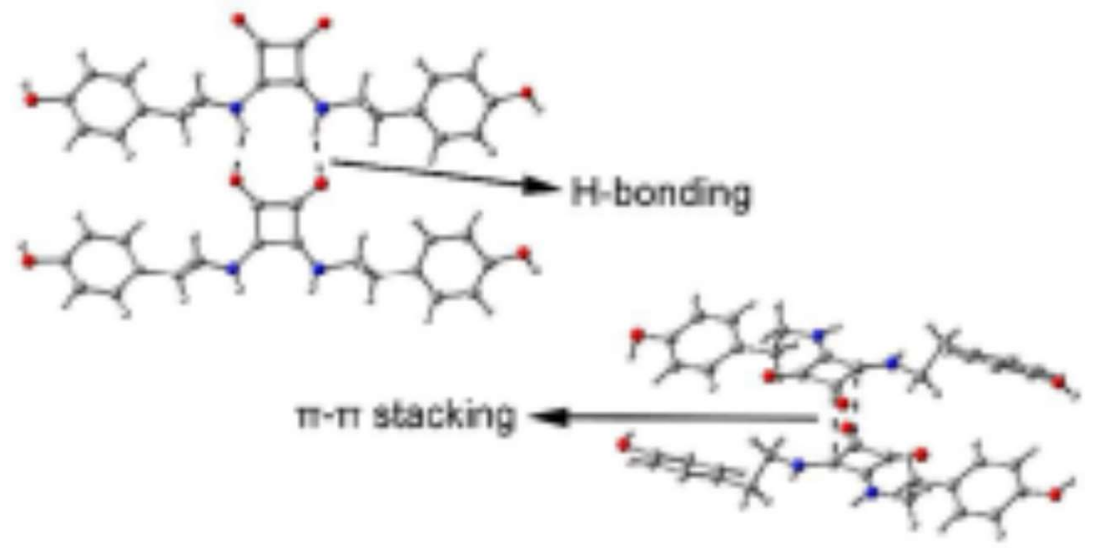

406 